\title{
Flow or No Flow? A Qualitative Study of Health Behavior Change Support System
}

\author{
Pasi Karppinen \\ University of Oulu \\ pasi.karppinen@oulu.fi \\ Anna-Maria Keränen \\ University of Oulu \\ anna-maria.keranen@oulu.fi
}

\author{
Tuomas Alahäivälä \\ University of Oulu \\ tuomas.alahaivala@oulu.fi \\ Tuire Salonurmi \\ University of Oulu \\ tuire.salonurmi@oulu.fi
}

\author{
Terhi Jokelainen \\ University of Oulu \\ terhi.jokelainen@ oulu.fi \\ Harri Oinas-Kukkonen \\ University of Oulu \\ harri.oinas-kukkonen@oulu.fi
}

\begin{abstract}
Recent studies about technology acceptance have highlighted the significance of hedonic values when examining consumer information systems. The flow experience is often taken as a theoretical construct to explain hedonic motivations in Web-related studies. However, regarding consumer healthcare information systems, the relevance of hedonic values has received relatively little attention. In this study OinasKukkonen's webflow model and its constructs are used to understand user experience in Behavior Change Support Systems (BCSSs) designed to prevent metabolic syndrome. Twelve participants were interviewed after using the system for ten weeks. Our findings suggest that in the area of consumer healthcare information systems, hedonic values are not as important as utilitarian values. This study demonstrates the value of the webflow model as a research framework and contributes to its further development. Methodologically, this paper contributes to a rarely used qualitative approach in studying the flow experience.
\end{abstract}

\section{Introduction}

There have been calls to address the global problem of lifestyle-related diseases. According to the World Health Organization (WHO) [1], eight risk factors account for $61 \%$ of cardiovascular-related deaths: high body mass index (BMI), blood glucose, cholesterol and blood pressure; low vegetable and fruit intake; and the use of tobacco and alcohol. These risk factors account for over three-quarters of cases of ischemic heart disease (IHD), which is a principal cause of mortality. Even though these risk factors are commonly associated with developed countries, $84 \%$ of the total global burden of the diseases they cause comes from middle and low-income countries. To a great extent, these risks are preventable [2].

The potential of information technologies to improve individuals' health through behavior change support systems (BCSSs) [3] has gained significant attention from academia and policymakers. By providing access and tools in individuals' own health information systems, designers can support how they can better manage their well-being.

A healthier lifestyle is not just a governmental goal; consumers themselves are eager to manage their health with the help of IT. There is a continuously growing number of Web and mobile applications, social health technologies, and portable devices such as heart rate monitors and accelerometers. Designers are interested in how to make these technologies more persuasive [4] so they can influence behavior change more effectively.

Payton et al. [5] argue that there has been a shift from being passive patients to active consumers of health information, healthcare devices, and monitoring systems. At the same time, scholars have faced exciting change in a way that information systems are not built solely for the needs of organizations. New types of IS users have emerged who are accustomed to seek entertainment and pleasure through IT services [6, 7]. Especially in the area of Internet research, the hedonic side of user experiences has been important since nearly the dawn of the World Wide Web [8]. One of the key theories used for understanding the hedonic side of the user experience is Csikszentmihalyi's flow theory [9]. Flow has played a major role when studying Internet usage and online consumer behavior [10-13]. However surprisingly enough, it has not been studied in the context of consumer health information technologies, as Or et al. [14] study reveals. In addition, Agarwal et al. [15] argue that studies of 
consumer health acceptance are limiting their focus to "patient demographics and health variables or general perceptions of the technology (e.g., ease of use and usefulness)."

Recent studies have shown the relevance of different persuasive systems design (PSD) software features and their categories to BCSS acceptance and adoption [16], and studies on the use of heart-rate monitors [17] have also produced promising results on the relationship between fluent user experience and perceived persuasiveness. However, the possible connection to the flow experience has not yet been thoroughly studied. Two persuasive technology studies based on the use of heart-rate monitors have offered promising inferences. When participants described their experiences in the heart-rate related study [18], one of the primary reasons for exercising was found to be feeling of enjoyment. Participants knew how they should exercise, but they did not always do it according to their best knowledge [18]. It is intriguing to speculate whether the heart-rate monitors actually helped participants to reach the flow state and to maintain it.

The research question is as follows: What can the flow experience reveal about actual BCSS usage? We have studied the BCSS user experience using OinasKukkonen's [10] webflow model, which has also been utilized in the healthcare information system domain previously [19]. This study utilizes a Web service called Onnikka, designed for individuals who either have a metabolic syndrome or are at risk of developing one, as a research vehicle. Onnikka was designed according to the Behavior Change Support System framework [3] and the Persuasive System Design model [4]. For this article, we studied the Onnikka's user experience by interviewing twelve participants after ten weeks of interaction.

The structure of the paper is as follows. First, we introduce the design models behind the developed system. After that, the flow theory and webflow model are explained. Chapter 4 outlines the research process. The results are presented in chapter 5. Chapter 6 includes a discussion, and the final chapter draws conclusions.

\section{Behavior Change Support Systems}

BCSSs have emerged as an important research domain in IS research. For example, applications promoting healthier lifestyles are typically BCSSs. Persuasive technology can be seen as a field of research, whereas a BCSS is an object of study [3]. Oinas-Kukkonen [3] defines BCSS as follows:
A behavior change support system (BCSS) is a socio-technical information system with psychological and behavioral outcomes designed to form, alter or reinforce attitudes, behaviors or an act of complying without using coercion or deception.

The O/C matrix developed by Oinas-Kukkonen [3] helps in analyzing the intent and the outcomes of a persuasive system. Successful outcomes in the matrix are the formation, alteration, or reinforcement of attitudes, behaviors, or compliance. The changes are also divided into three categories: a change in the act of complying, a behavior change, or an attitude change (C-, B-, and A-change).

The Persuasive Systems Design (PSD) model is the state-of-the-art design and evaluation tool for BCSSs [3]. The PSD model includes a set of seven postulates concerning persuasive systems, as well as the analyses of the intent, event, and strategy of persuasion. The PSD model also defines potential software features for BCSSs, which are divided into four categories: primary task support, computer-human dialogue support, perceived system credibility, and social influence [4].

As a part of studying the prevention of metabolic syndromes through new lifestyle intervention methods, the Onnikka BCSS was developed. In designing the system, the Persuasive Systems Design [4] process was followed. The Ethics Committee of the Oulu University Hospital granted permission for the study on 26 March 2012. Two amendments were approved on 23 November 2012 and 18 February 2013.

The idea behind Onnikka was to provide a channel for users to receive new informational content provided by health professionals every week and the ability to keep track of the individuals' lifestyle change progress by submitting personal entries about weight loss, motivation, eating habits, and exercising. Besides the Web-based application interface, e-mail messages are used to interact with the users.

An analysis of the persuasion context [4] was conducted when designing the system. The analysis of the intent included recognizing the initiators behind the project as the persuaders of system, and the system intent ultimately to reach an A-change in the attitudes of the users since a permanent lifestyle change is needed for sustainable weight loss [20]. Based on the users' backgrounds, they were expected to be forming, altering, or reinforcing their existing attitudes. The analysis of the persuasion event included recognizing the user profiles, the use context, and the appropriate technological details of the system.

The PSD principles were widely utilized in the design process. The software features related to the primary task category, such as tunneling, selfmonitoring, and tailoring, were emphasized in the design of the individual features. From the dialogue 
support category of features, reminders to use the system were utilized, as well as praising the user on good weight loss performance. The system credibility principles were paid less attention because the parties behind the system were considered already to be trustworthy among the users. The persuasive aspect of social interaction was implemented through the discussion part of each weekly information session. The implemented features of each category are summarized in Table 1.

\section{Table 1. The persuasive features in the BCSS} studied

\begin{tabular}{|l|l|}
\hline Primary Task Support & Dialogue Support \\
Reduction & Reminders \\
Tunneling & Suggestion \\
Tailoring & Liking \\
Self-monitoring & \\
\hline Credibility Support & Social support \\
$\begin{array}{l}\text { Trustworthiness } \\
\text { Expertise } \\
\text { Surface credibility }\end{array}$ & Social learning \\
Verifiability & Normative influence \\
\hline
\end{tabular}

Enhancing an individual's eating behavior is one of the major factors in maintaining weight loss [20]. Because not all persons experiencing a metabolic syndrome have a specific need for counseling about eating behaviors, counseling was tailored to be accessible only to a certain group of users based on their behavioral profiles. Implementation details of Onnikka are described in [21].

\section{Flow user experience and the webflow model}

Flow can be described briefly as a joyful experience, where an individual is fully focused, involved, and absorbed in an activity. Csikszentmihalyi [22] identifies six components of flow. Elements relating to total immersion into the activity are the centering of attention and loss of selfconsciousness, merging action and awareness. A person experiencing flow has a strong feeling of control, and the demands are clear and noncontradictory. The steps of the action feel natural, and they occur without consciously thinking about it. The action runs smoothly without much effort to achieve a person's goals. The experience is enjoyable and rewarding in itself $[9,22,23]$.

Flow theory has found a companion in the research fields of computer games [24] and virtual worlds [25]. They can be seen as natural allies because, in these fields, an IT artifact is at the very core of creating the flow experience. In the BCSS field, the system is mostly a tool to accomplish something beyond the IT artifact. Pilke [26] studied flow experiences in information technology use and showed that flow is not familiar only when playing games or surfing in the Web. Based on her interviews, writing, image editing, and programming can also produce flow. Finneran and Zhang [27] developed the person-artifact-task-model to take this notion further.

There is a high level of agreement on the definition of flow itself [23], but as Finneran and Zhang [28] argue in their study, there is not a consensus about computer-mediated environments of what the antecedents or consequences of flow experience are. For Pilke [26], flow is suited for examining the overall quality of the user experience. Korzaan [12] predicted that flow has a correlation with online purchase intentions. Koufaris [11] found a connection between flow and the intention to return to a website. Flow theory has also been utilized, for example, by Webster and Ahuja to study Web navigation and disorientation [29].

Finneran and Zhang [28] argue that difficulties arise due to flow's holistic nature, thus it is challenging to isolate and study components separately. As a solution, they suggest using qualitative techniques [28]. In this study, Oinas-Kukkonen's [30] webflow model is used as a foundation for semistructured interviews. He defines flow as follows:

Webflow is an optimal perceived user experience which improves a web user's orientation and navigational use, as well as vice versa, and which is predicted by balanced user skills and the feeling of the web to be enjoyably challenging, the feeling of being in control of web use, and the perceived ease of use and usefulness of the web.

We adopted the webflow questions from [19], and the questions were modified based on a pilot study where test users, researchers, and system designers were interviewed. Typical wordings of the questions are described in Appendix 1. We did not use enjoyment as a signifier of flow; instead, we asked directly whether the subject had experienced flow while using the system. If a respondent did not understand the meaning of flow, we clarified it for him/her.

Differences between individuals can produce different flow experiences even though the activity is the same [28]. Csikszentmihalyi [9] uses the term autotelic personality to describe a person's ability to experience flow. Although autotelic personality is one of the essential elements of Csikszentmihalyi's flow theory [9], it has been rarely used in IS models [28]. In this study, in addition to the question of flow, questions regarding autotelic personality were also asked. Further, the subjects were asked to consider whether 
they perceived Onnikka as a hedonic or a utilitarian system.

The webflow model's survey items are described in Table 2. Webflow-based surveys have also been successfully conducted in mobile environments, as in early WAP [31] and modern smartphone implementations [19], for instance.

Table 2. Survey questions of the webflow model, adapted from [19]

\begin{tabular}{|l|l|l|}
\hline Q1 & $\begin{array}{l}\text { Question } \\
\text { I feel that this Web service is } \\
\text { easy to use. }\end{array}$ & $\begin{array}{l}\text { Ease of } \\
\text { use }\end{array}$ \\
\hline Q2 & $\begin{array}{l}\text { I often feel uncertainty when } \\
\text { using this Web service. }\end{array}$ & Control \\
\hline Q3 & $\begin{array}{l}\text { I am skilled at using Web } \\
\text { services. }\end{array}$ & Skills \\
\hline Q4 & $\begin{array}{l}\text { In my opinion, it is easy to } \\
\text { perceive the information } \\
\text { content and structure of this } \\
\text { Web service. }\end{array}$ & Orientation \\
\hline Q5 & $\begin{array}{l}\text { It is enjoyable to navigate in } \\
\text { this Web service. }\end{array}$ & Navigation \\
\hline Q6 & $\begin{array}{l}\text { In my opinion, this is a well- } \\
\text { designed Web service. }\end{array}$ & Usefulness \\
\hline Q7 & $\begin{array}{l}\text { This Web service enables } \\
\text { me to learn new things. }\end{array}$ & Learning \\
\hline Q8 & $\begin{array}{l}\text { This Web service is } \\
\text { enjoyably challenging. }\end{array}$ & Challenge \\
\hline Q9 & $\begin{array}{l}\text { I feel totally focused when I } \\
\text { am using this Web service. }\end{array}$ & $\begin{array}{l}\text { Focused } \\
\text { attention }\end{array}$ \\
\hline Q10 & $\begin{array}{l}\text { Using this Web service is } \\
\text { enjoyable. }\end{array}$ & $\begin{array}{l}\text { Flow } \\
\text { experience }\end{array}$ \\
\hline
\end{tabular}

\section{Research process}

This research case is part of a larger ongoing study named "Prevention of Metabolic Syndrome (PrevMetSyn)," which is a randomized lifestyle intervention study with two different counseling interventions: group 1, with eight group visits, and group 2, with two group visits. Group 3 serves as a control group and used Onnikka without any face to face counseling. The study subjects are overweight or obese, working age (20-60 years) females and males with or without metabolic syndrome. A description of the subjects' demographic data and usage of Onnikka in the data set in this paper are described in Table 3.

This paper's focus group comprises of the first 37 study subjects who started using Onnikka in March 2013. Twelve subjects were selected for interviews that took place between the 5 th and 7 th of June 2013. The interview was conducted after 10 weeks of use. The semi-structured interviews were conducted via phone.
Table 3. Subjects, their demographic data, and frequency of using Onnikka

\begin{tabular}{|c|c|c|c|c|c|c|}
\hline$I D$ & Gender & Age & $G$ & $T$ & Last & Visits \\
\hline 11 & Male & 45 & 1 & $Y$ & May 27 & 82 \\
\hline 12 & Female & 50 & 1 & $\mathrm{Y}$ & June 4 & 33 \\
\hline 13 & Male & 41 & 1 & $\mathrm{~N}$ & June 5 & 21 \\
\hline 14 & Female & 48 & 1 & $\mathrm{~N}$ & April 15 & 11 \\
\hline 21 & Male & 46 & 2 & $\mathrm{Y}$ & May 29 & 23 \\
\hline 22 & Female & 59 & 2 & $\mathrm{Y}$ & May 31 & 17 \\
\hline 23 & Male & 56 & 2 & $\mathrm{~N}$ & June 3 & 25 \\
\hline 24 & Female & 57 & 2 & $\mathrm{~N}$ & May 28 & 23 \\
\hline 31 & Male & 35 & 3 & $\mathrm{Y}$ & April 2 & 4 \\
\hline 32 & Female & 46 & 3 & $Y$ & April 3 & 3 \\
\hline 33 & Male & 53 & 3 & $\mathrm{~N}$ & May 27 & 17 \\
\hline 34 & Female & 58 & 3 & $\mathrm{~N}$ & June 4 & 27 \\
\hline \multicolumn{7}{|c|}{$\begin{array}{l}\text { G: Counseling group, 1/2/3 } \\
T: \text { Tailored information, Yes }\end{array}$} \\
\hline
\end{tabular}

We use an interpretive research approach that leans ontologically to a social construct of reality; i.e., it is gained through language, consciousness, and shared meaning. The guidelines of Myers and Newman [32] were applied for conducting the interviews.

Situating the researcher as actor: At the beginning of the interview, the situation and how the data was to be used were described to the subjects. Demographic questions were asked, and the interviewer used his own details as an example. It helped in positioning the researcher and in relaxing the subjects. The interviewer made it possible to contact him afterward.

Minimize social dissonance: In Finland, where the interviews were conducted, the society is relatively "flat," so no extra preparatory effort was made to minimize social dissonance. However, during the conversation, the interviewer emphasized whenever possible the life situation of the subject and openly made similar remarks concerning his own life.

Represent various "voices": The strategy for choosing the interviewed subjects was to obtain one active and non-active male and female from all of the subgroups. It was also aimed to obtain the same number of subjects who had tailored information and those who did not. As there was such a small focus group $(n=37)$, it was hard to find perfect representatives for all groups. In groups 1 and 2, there were not as many inactive users as in 3 .

Everyone is an interpreter: This study is an interpretive case study, and it holds the idea that the world is socially constructed. The results can be seen as a narratives, but still we consider them convincing stories that bring relevant information to the IS knowledge base.

Use of mirroring in questions and answers: Even though we had a semi-structured list of questions, 
mirroring was used whenever it was needed. During the course of the interviews, the order of questions varied according to the themes that the subject described.

Flexibility: A single interview took approximately 30 minutes. Most of those interviewed were able to give all the time needed for the interview. One subject was in a time-constrained situation, so the interview was done more rapidly than with the others.

Confidentially of disclosure: For the recordings, no names were included; only research numbers that help to link the respondents to other data and usage of Onnikka were used. The numbers in this study are yet again different from the original research numbers.

\section{Results}

In this chapter, we present the results by going through a case interview. Some of the quotations include comments in the brackets, which are interviewer's interpretations.

Ease of Use. All of the subjects felt that Onnikka was easy to use. Two subjects described that they had some challenges at the beginning, but they learned how to use the Web-based system eventually. A few said that they adjusted their interaction with the system so that, if they felt that there were features that were not that easy to use, users lessened their use of it. One respondent was frustrated with her long and difficult password, so she used the system rarely than she would have liked to. In spite of that, she felt that the system was easy to use. Some replies indicated that it was hard for participants to draw the line between the usability and cumbersome work.

34: "I've made it easy for myself. I don't write that much in the system. I don't use the food diary anymore, for instance."

Nearly all of the users complained about the use of Onnikka's food diary, which was often said to require too much effort. Other than that, the system was generally praised as being very easy to use.

Control. The second webflow question handled the feeling of insecurity. Only one respondent clearly stated that she sometimes felt insecure while using the system. One respondent did not answer this question. Subject 11 felt some insecurity in the beginning but gained control after he learned how to use the system.

11: "Maybe at first I felt [insecure], but not anymore. Nowadays, I use it with my smart phone. I have it in my bookmarks, and in the morning, when I go to the scale, I turn it on immediately."

Skills. Surprisingly, after giving similar answers about ease of use and the feeling of control, the respondents estimated their skills very differently from one another. Three subjects could not say whether they had better skills than the others. Four felt that they were better-than-average users, and five claimed that their skills were worse than those of regular people. It seems that some participants had made a big effort to use Onnikka.

32: I'm definitely not skillful. I don't know English to begin with. I don't surf to any of those sites [on the Web]."

Most of the participants are middle-aged, and the spectrum of their use history was wide. Some are very skillful, while others use computers only when they have to.

Orientation. This question addressed how easy it was to understand the information that Onnikka offered. Almost all of the answers were straightforward. Only one subject was not able to answer this question. The participants felt that it was easy to comprehend the information provided by the Web system.

28: “Yes. I don't get any feeling of being lost. My workplace's website is far more complicated... but then again, it has to cover so many different areas from this."

Probably the reason that we received such homogenous answers is because Onnikka was developed straightforwardly for one purpose.

Navigation. Nearly all the participants felt that it was easy to navigate in Onnikka. One participant had small problems in the beginning but learned how to navigate in the long run. One respondent found an illogical path when trying to find archived information from previous training weeks but managed to take that into account after discovering it. One subject was disappointed in the persuasiveness of the system, which affected nearly all of his answers, including navigation:

13: "It's so-so... whether it is or not [easy to navigate]. For me, the whole use leaves half short because the system isn't that inspiring."

Usefulness. The Web-based system was reported to be useful for all users except for one subject. However, two participants' answers revealed that they found usefulness on a more general rather than a personal level.

32: “Yes, it's useful... but maybe I would have let it slip through my fingers if I had come across it [outside the research project]."

The reasons for the system's usefulness varied among the subjects. For example, some were keen on monitoring their own progress, while others liked to gather new information. Many had difficulty underlining how much of their progress was due to the system itself.

Learning. Subjects had problems making distinctions between their personal and general views. 
Six respondents felt that they had learnt new things. The other half felt that the information was familiar from other sources as well. Typically, users reflected their learning to gain new information. Only one participant evaluated learning beyond the information level.

21: “You'll learn if you do all the weekly tasks actively. At the same time, it makes this [Web system] even more personal."

Challenge. Half of the respondents felt that Onnikka was challenging enough.

33: "Yes, it gives enough of a challenge. It doesn't stop at one spot; rather, it brings new stuff all the time. When, for instance, the theme was exercising, it activated me more [to move]. It starts to become more or less like a habit. It's been good with that."

One subject pointed out that she could adjust weekly task challenges easily by herself. Four participants were expecting that Onnikka would be more challenging. One subject was explicitly hoping for better dialogue support to get a motivating response from the weekly assignment.

Focused attention. This question assessed how focused users were when they used the system. This question made the respondents review the entire time span of use. Half of the participants said that they were focused most of the time, if not all of it. Four subjects admitted that they had difficulty focusing in using the system.

14: "I'm an entrepreneur and quite busy all the time... I run through it at home or at work. I don't focus on it too much."

Two participants said that they were more focused at the beginning of the project but recently had not been as focused when using the system.

Flow experience. The interviewer asked if the subjects understood what the flow experience meant and described it when necessary. Additionally, the subjects were asked how easy it was for them to experience flow in other activities, such as work or hobbies. In this study, people did not have difficulty understanding flow. Quite often, the subjects gave fast and straightforward answers.

14: “No, I haven't been able to reach flow... [following question about personal ability to experience flow]. Yes, I do get it at work."

Three users said that they have experienced flow when using Onnikka. All of them felt that it was easy to achieve flow in other activities as well. Four participants thought that they could reach flow in other activities, but not when using Onnikka. Five subjects said that it was difficult for them to experience flow to begin with, and for two of them it was not because their own inability.
12: "I think that, for me, it's not that easy. At work, I get interrupted all the time, and at home, I have small children. I'm constantly holding my antennas up... You should ask this question again after 10 years."

Other questions. Finally, the participants were asked to give their opinions about whether the system was hedonic or utilitarian. All of the subjects said that they found Onnikka as more of a utilitarian rather than a hedonic system. Surprisingly, only one respondent stated that she would want to experience more fun when using the system. Four respondents underlined that implementing more entertaining elements would be a step in the wrong direction.

21: "It goes more to the utility side. Losing weight is serious business. Joyful things must be thought through thoroughly. Bad humor annoys more than it makes you laugh.”

\section{Discussion}

This paper has studied user flow experience in Behavior Change Support Systems using the webflow model and constructs. According to the results, only three participants out of twelve have experienced flow when using the Onnikka Web system. The collected data does not reveal one particular recognizable path that would explain either antecedents or consequences of flow experience in BCSS use. Naturally, it is not the purpose of interpretive research to find correlations between theoretical constructs, and our findings should not be taken as such, but the results still clearly indicate that flow does not play as fundamental a part in the BCSS user experience as expected.

Next, we will discuss what the results reveal about the interplay between flow and BCSS using OinasKukkonen's [10] webflow model. After this, we will discuss experiences of using the webflow model qualitatively.

During the interviews, webflow questions were asked in four separate clusters or themes. When following the preplanned structure of the interview, the first questions concerned control, ease of use, and skills.

In the webflow [10] model, the feeling of being in control over the system is an antecedent of flow. In our case, nearly all of the participants reported experiencing it. According to the results, the feeling of control was connected with the ease of use. The same subjects who had feelings of insecurity also did not think that the system was easy to use in the beginning.

Perceived ease of use and usefulness has been predominant construct in explaining and predicting technology acceptance $[33,34]$. All of the subjects in this study claimed that the system was easy to use. 
Even those participants who had not used Onnikka much did not comment that it was too difficult to use. In the webflow model, ease of use is an intermediate variable between skills and flow [10, 30], and it hypothesized that, when a user has high skills, it implies that the system is easy to use, which in turn can cause flow. In this study, however, the subjects' skill levels in using Web-based systems in more general varied substantially, so this hypothesis does not resonate with the collected data. Of the three subjects who experienced flow when using Onnikka, two of them reported not having enough skills as that of an average person. This is rather unanticipated because, for instance, in Pilke's [26] study, the most frequently mentioned obstacle for the flow experience was insufficient skills in using the system through its use interface. One possible explanation is that, since Onnikka was designed to be as transparent as possible, a user's skill level did not make a difference to the user experience. Skill is the only webflow construct that was not supported for the subjects who felt flow. Regarding the flow theory, the most crucial antecedent is that the skills and challenges are in balance with the action. However, as Finneran and Zhang [28] ask, what kind of skills actually should be measured when studying the flow experience in ICT? In the case of BCSS, would it be more meaningful to ask about the life management of the particular area the system supports?

The next theme of the webflow questions dealt with the orientation and navigation of the system. In the webflow model, orientation and navigation are antecedents as well as consequences of flow [10, 30]. According to Oinas-Kukkonen's webflow definition [30], orientation and navigational use are improved by flow, but in return, both of them enhance flow. Neither navigation nor orientation stimulated any strong opinions or rich feedback from the subjects. Both areas were considered to work well without any major hindrances. Webster and Ahuja [29] use flow constructs to measure whether disorientation or navigation had an effect on user performance and intention to use websites. Their exact word is engagement instead of flow partly because the data was collected in an experimental setting, where it is questionable whether the subjects are able to reach the flow state [29]. Webster and Ahuja [29] find a strong relationship between disorientation, engagement, performance, and intention to use a website. Interestingly, they find no difference in disorientation between the simple navigation system and the basic global navigation system [29]. This may imply that, despite the design of a small and closed Web-based system such as Onnikka, the case system here, the planning of the navigation is no less important than in vast systems.

The third cluster of webflow constructs included questions about usefulness, learning, and challenges. In the webflow model $[10,30]$ usefulness is an intermediate variable between challenges and flow. Higher challenges mean that consumers perceive the system as useful, which can in turn cause flow [10]. This study shows somewhat different results than expected. Four respondents stated that the system was useful, but at the same time, they were hoping that the system would challenge them more. Usefulness, the most powerful construct for predicting technology acceptance in the organizational context [33], was not a straightforward element in our case. Regarding Onnikka, usefulness was often considered to have a wider meaning than we anticipated. Instead of narrowing it to losing weight, some described usefulness from non-subjective angles.

In the webflow model $[10,30]$ learning is an intermediate variable between skills and the system because users may learn new skills through using the system. In our study, learning does not have such an obvious link with the skills, but then again, only Web skills were enquired about, as stated earlier. According to our results here, learning, rather, goes hand in hand with the challenges instead of skills. Subjects who saw Onnikka as challenging enough claimed to learn new things and vice versa. Only one participant out of twelve said that she learned new things from Onnikka but also wanted to be challenged more. Skadberg and Kimmel [35] find in their study that increased learning is a consequence of flow and that learning is the driver that leads to a change in attitude and behavior. OinasKukkonen claims [19] that learning actually plays a dual role when the system is used for acquiring more knowledge. When a user learns, (s)he more likely experiences flow, and when (s)he perceives flow, (s)he more likely perceives to learn [19]. Half of the subjects received additional health informational content that enhanced their eating habits. From the responses, it was not explicit whether the tailoring had any effect on webflow constructs. Presumably, it was considered to have the most likely match with learning, but our data do not support this.

The last set of webflow questions in the interviews concerned focused attention and flow. In the webflow model [10, 30], focused attention has a direct effect on flow, but it is also an intermediate variable between challenges and the system because, through persuasive content and functionality, user attention focus may rise [10]. In this study, focused attention and challenges do not interlink clearly together. It is possible that, since Onnikka also provides tasks outside of the system, completing them does not require focusing on the 
actual system use. Eight subjects said that they perceived to have been focused when they used Onnikka, but only three of them stated that they had reached flow.

As stated before, all constructs but "Web skills" were supported by the results from those participants who were perceived to have achieved a flow state. Interestingly, two participants reported that they did not achieve a flow state even though their replies provided strong support for all of the model's other constructs. In their case, the difference-maker was the question about autotelic personality. Based on our findings here, autotelic personality seems to be an important factor in flow research. If this area is neglected, a researcher might end up searching for answers from the IT artifact when the explanation lies in the user's personality.

According to Csikszentmihalyi [9], once a person has experienced flow, (s)he will increase efforts to feel it again. In Onnikka's case, the most frequent user also experienced flow, but still there is not a clear trend that would support this conclusion for the whole study group. Participants in group 1 seemed to gain clear benefits from the group sessions. In particular, subject 13, who openly hated Onnikka, had used the system more often than three respondents in group 3 . Venkatesh et al.'s [33] study shows that social influence (by which they mean the influence of an authority) is correlated to technology acceptance when the use is not voluntary. One possible explanation is that the subject felt obliged to use Onnikka when participating group sessions.

In this study, subjects were not directly asked how persuasive they found Onnikka to be because, we had noted in the pilot study that asking this from the participants caused deadlocks in the interview sessions and thus would have required more explanation. Moreover, perceived persuasiveness does not necessarily have much predictive power for technology adoption in a BCSS setting [36]. Nevertheless, two subjects clearly stated that the system lacks persuasiveness, which influenced both of them negatively throughout the study. Unfortunately, we did not study whether the flow experience also affected the perception of the system's persuasiveness.

The flow experience is not a stagnant state, and it can wear off over time, as Magni et al.'s [34] study claims. Their results show that, when exploring new technology, the importance of utilitarian values increases while the flow experience decreases in the long run. In our study, the best example of flow experience variation was found in subject 11's experiences. He felt in the beginning that Onnikka was not easy to use and was also insecure when using it. After the slow start, he started to bloom, and by ten weeks he had double the number of entries to the system compared to the second most frequent visitor.

The results indicate that, despite its well-designed software features and usability, the Onnikka system did not cause a flow experience for most of the participants. This finding contradicts the recent study by Venkatesh et al. [37], who argue that, in most nonorganizational contexts, hedonic motivation is a critical determinant of behavioral intention, and they found it to be a more important driver of use than performance expectancy. Our qualitative data shows quite the opposite, and the finding reveals that the area of consumer information systems is far more complex than is generally currently assumed.

\section{Conclusions}

This study's objective was to investigate the flow user experience in Behavior Change Support Systems. The research case explored the Web-based system called Onnikka, which was developed for the prevention of metabolic syndromes. Data were gathered from real users by conducting semi-structured interviews. Questions were based on the webflow model developed by Oinas-Kukkonen [10, 30]. It was speculated whether hedonic values would somehow stand out from the data, since the system was built for consumers. Pilke [26] claims in her study that facilitating flow should be the goal of user interaction design. The results of this study indicate that the importance of the flow experience was not as central for BCSS use as suggested. Our study revealed that users do not expect consumer information systems to serve merely hedonic needs. On the contrary, it seems to be that some participants had to make an extra effort to climb over the first hurdle to use the system accordingly.

The study has multiple limitations that need to be taken into account. The validity of our findings can be questioned due to the relatively small sample size. Second, since webflow constructs were originally used for quantitative data gathering, some of the questions produced too little material for deep qualitative analysis. Partially because of the data's descriptive scarcity, this study cannot fully answer the questions that it evokes. If hedonic values are not the key motivators of BCSS use, what are?

Our research has a strong focus on IT artifacts, and we hope that presented findings will provide useful insights for practitioners. For academia, this study encourages researchers to gather both quantitative and qualitative data when conducting flow-related studies. Flow is a very holistic sensation that does not express its antecedents or consequences easily. In this particular case study, the most intriguing findings are 
the anomalies that do not fit the current body of scientific knowledge. In this study, one of the subjects in particular is an enigma. She probably had the most insufficient computer skills in the group, felt insecure while using the system, and faced problems each time she logged into the system. She was not challenged enough by the system nor did she perceive to have learnt anything. She was part of the control group, which did not get any face to face counseling. She had not experienced flow when using the system even though the experience is familiar to her. Against all odds, she was the third most frequent user of Onnikka among the subjects. Our data indicates that people can make unexpected efforts in IS use for reasons that are yet hidden. There is an urgent need for longitudinal qualitative studies that embrace the holistic user experience of BCSS in the area of consumer healthcare information technology. With the current paradigm, scholars tend to emphasize for the hedonic values in studying consumer information systems. This study shows that the current understanding is far too simplistic, and especially in the area of healthcare technology, targeting primarily based on hedonistic features can perhaps even do more harm than good.

\section{Acknowledgements}

We wish to thank the contribution of the PrevMetSyn research consortium, especially Markku Savolainen, Maija-Leena Huotari, Heidi Enwald and Kreetta Askola. We also would like to thank Sitwat Langrial for his insightful comments for this paper. This research is part of OASIS research group of Martti Ahtisaari Institute, University of Oulu.

\section{References}

[1] World Health Organization. "Projections of mortality and burden of disease, 2004-2030", http://www.who.int/healthinfo/global_burden_disease/project ions/en/, 2008, [Last accessed: 02.05.2013].

[2] K. Strong, C. Mathers, S. Leeder, and R. Beaglehole. "Preventing chronic diseases: How many lives can we save?", The Lancet 366, 2005, pp. 1578-1582.

[3] H. Oinas-Kukkonen, "A foundation for the study of behavior change support systems," Personal and Ubiquitous Computing 17(6), 2013, pp. 1223-1235.

[4] H. Oinas-Kukkonen, and M. Harjumaa, "Persuasive Systems Design: Key Issues, Process Model, and System Features", Communications of the Association for Information Systems 24(1), 2009, pp. 485-500.

[5] F.C. Payton, G. Pare, C. M. Le Rouge, and M. Reddy, "Health Care IT: Process, People, Patients and
Interdisciplinary Considerations", Journal of the Association for Information Systems 12(2), 2011.

[6] T. Vartiainen, and T. Tuunanen, "Co-Creation of Value for IT-Enabled Services: A Case of Geocaching", System Sciences (HICSS), 2013 46th Hawaii International Conference on, IEEE, 2013, pp. 1093-1102.

[7] H. Van der Heijden, "User Acceptance of Hedonic Information Systems", MIS quarterly 28(4), 2004, pp. 695 704.

[8] D.L. Hoffman, and T.P. Novak, "Marketing in Hypermedia Computer-Mediated Environments: Conceptual Foundations", The Journal of Marketing 60(3), 1996, pp. 5068.

[9] M. Csikszentmihalyi, and I.S. Csikszentmihalyi, Optimal experience: Psychological studies of flow in consciousness, Cambridge University Press, Cambridge, 1992.

[10] H. Oinas-Kukkonen, "Balancing the Vendor and Consumer Requirements for Electronic Shopping Systems", Information Technology and Management 1(1-2), 2000, pp. 73-84.

[11] M. Koufaris, "Applying the Technology Acceptance Model and Flow Theory to Online Consumer Behavior", Information systems research 13(2), 2002, pp. 205-223.

[12] M.L. Korzaan, "Going with the Flow: Predicting Online Purchase Intentions", Journal of Computer Information Systems 43(4), 2003, pp. 25-31.

[13] A. Kamis, M. Koufaris, and T. Stern, "Using an Attribute-Based Decision Support System for UserCustomized Products Online: An Experimental Investigation”, MIS Quarterly 32(1), 2008.

[14] C.K. Or, and B. Karsh, "A Systematic Review of Patient Acceptance of Consumer Health Information Technology", Journal of the American Medical Informatics Association 16(4), 2009, pp. 550-560.

[15] R. Agarwal, C. Anderson, J. Zarate, and C. Ward, "If We Offer it, Will They Accept? Factors Affecting Patient use Intentions of Personal Health Records and Secure Messaging", Journal of Medical Internet Research 15(2), 2013.

[16] T. Lehto, T., H. Oinas-Kukkonen, and F. Drozd, "Factors Affecting Perceived Persuasiveness of a Behavior Change Support System”, ICIS 2012 Proceedings: Human behavior in IT adoption and use, 2012.

[17] K. Segerståhl, and H. Oinas-Kukkonen, "Distributed user experience in persuasive technology environments", Persuasive Technology, Springer Berlin Heidelberg, 2007, pp. 80-91. 
[18] M. Harjumaa, K. Segerståhl, and H. Oinas-Kukkonen, "Understanding Persuasive Software Functionality in Practice: A Field Trial of Polar FT60", Proceedings of the 4th international conference on persuasive technology, ACM, 2009.

[19] H. Oinas-Kukkonen, T. Raisanen, K. Leiviska, M. Seppanen, and M. Kallio, "Physicians' User Experiences of Mobile Pharmacopoeias and Evidence-Based Medical Guidelines", International Journal of Healthcare Information Systems and Informatics (IJHISI) 4(2), 2009, pp. 57-68.

[20] A. Keränen, M.J. Savolainen, A.H. Reponen, M.L Kujari, S.M. Lindeman, R.S. Bloigu, and J.H. Laitinen, "The Effect of Eating Behavior on Weight Loss and Maintenance during a Lifestyle Intervention”, Prev. Med. 49(1), 2009, pp. 32-38.

[21] T. Alahäivälä, H. Oinas-Kukkonen, and T. Jokelainen, "Software Architecture Design for Health BCSS: Case Onnikka", Persuasive Technology, Springer, 2013, pp. 3-14.

[22] M. Csikszentmihalyi, and I. Csikszentmihalyi, Beyond boredom and anxiety: The experience of play in work and games, Jossey-Bass, San Francisco, 1975.

[23] S. Engeser, and A. Schiepe-Tiska, "Historical Lines and an Overview of Current Research on Flow", Advances in Flow Research, Springer New York, 2012, pp. 1-22.

[24] M.D. Hernandez, “A Model of Flow Experience as Determinant of Positive Attitudes Toward Online Advergames", Journal of Promotion Management 17(3), 2011, pp. 315-326.

[25] L. Goel, N. Johnson, I. Junglas, and B. Ives, "Predicting Users' Return to Virtual Worlds: A Social Perspective", Information Systems Journal 23(1), 2013, pp. 35-63.

[26] E. Pilke, "Flow Experiences in Information Technology use", International Journal of Human-Computer Studies 61(3), 2004, pp. 347-357.

[27] C.M. Finneran, and P. Zhang, "A person-artefact-task (PAT) Model of Flow Antecedents in Computer-Mediated Environments", International Journal of Human-Computer Studies, 59(4), 2003, pp. 475-496.

[28] C.M. Finneran, and P. Zhang, "Flow in ComputerMediated Environments: Promises and Challenges", Communications of the Association for Information Systems 15(82), 2005.

[29] J. Webster, and J.S. Ahuja, "Enhancing the Design of Web Navigation Systems: The Influence of User Disorientation on Engagement and Performance", MIS Quarterly 30(3), 2006, pp. 661-678.

[30] H. Oinas-Kukkonen, "The Construct of Webflow for Capturing the Web User Experience", Proceedings of the
Third ACM International Web Science Conference (WebSci 11), 2011, pp. 1-2.

[31] H. Oinas-Kukkonen, "Mobile Electronic Commerce through the Web", Second international conference on telecommunications and electronic commerce (ICTEC), Nashville, Tennessee, USA, 1999, pp. 69-74.

[32] M.D. Myers, and M. Newman, "The Qualitative Interview in IS Research: Examining the Craft", Information and organization 17(1), 2007, pp. 2-26.

[33] V. Venkatesh, M.G. Morris, G.B. Davis, and F.D. Davis, "User acceptance of information technology: Toward a unified view", MIS quarterly 27(3), 2003, 425-478.

[34] M. Magni, M. Susan Taylor, an V. Venkatesh, "'To play or not to play': A cross-temporal investigation using hedonic and instrumental perspectives to explain user intentions to explore a technology", International journal of humancomputer studies 68(9), 2010, pp. 572-588.

[35] Y. Xia Skadberg, and J.R. Kimmel, "Visitors' Flow Experience while Browsing a Web Site: Its Measurement, Contributing Factors and Consequences", Comput. Hum. Behav. 20(3), 2004, pp. 403-422.

[36] T. Lehto, H. Oinas-Kukkonen, T. Pätiälä, and O. Saarelma, "Consumers' perceptions of a virtual health check: An empirical investigation”, ECIS 2012 Proceedings, 2012.

[37] V. Venkatesh, J. Thong, and X. Xu, "Consumer acceptance and use of information technology: extending the unified theory of acceptance and use of technology", MIS Quarterly 36(1), 2012, pp. 157-178.

\section{Appendix 1}

This section provides the typical wording of the webflow questions asked during the interviews. The numbering reflects the webflow instrument presented in chapter 3 .

Q1. Has the use of Onnikka felt easy?

Q2. Have you felt insecure when you've used Onnikka?

Q3. On a general level, are you a skillful user of Web systems?

Q4. Is it easy to understand the information that Onnikka offers?

Q5. Is it easy to navigate Onnikka's information?

Q6. Do you feel that Onnikka is useful?

Q7. Can you learn new things through the use of Onnikka?

Q8. Is Onnikka challenging enough?

Q9. Have you been totally focused when you have used Onnikka?

Q10. Have you ever experienced flow when you have used Onnikka? Do you know what I mean by the flow experience? There are individual differences in how easy it is to get to the flow state. How easy or hard is it for you?

Q11. In your opinion, is Onnikka a hedonic or a utilitarian system? 